\title{
Controlling Magnetic Anisotropy in a Zero-Dimensional $S=1$ Magnet Using Isotropic Cation Substitution
}

\author{
Jamie L. Manson,* Samuel P. M. Curley, Robert C. Williams, David Walker, Paul A. Goddard,* \\ Andrew Ozarowski, Roger D. Johnson, Anuradha M. Vibhakar, Danielle Y. Villa, Melissa L. Rhodehouse, \\ Serena M. Birnbaum, and John Singleton*
}

Cite This: J. Am. Chem. Soc. 2021, 143, 4633-4638

Read Online

ACCESS | 네 Metrics \& More | 回 Article Recommendations | sl Supporting Information

ABSTRACT: The $\left[\mathrm{Zn}_{1-x} \mathrm{Ni}_{x}\left(\mathrm{HF}_{2}\right)(\mathrm{pyz})_{2}\right] \mathrm{SbF}_{6}(x=0.2 ;$ pyz $=$ pyrazine) solid solution exhibits a zero-field splitting $(D)$ that is $22 \%$ larger $\left[D=16.2(2) \mathrm{K}\left(11.3(2) \mathrm{cm}^{-1}\right)\right]$ than that observed in the $x=1$ material $\left[D=13.3(1) \mathrm{K}\left(9.2(1) \mathrm{cm}^{-1}\right)\right]$. The substantial change in $D$ is accomplished by an anisotropic lattice expansion in the $\mathrm{MN}_{4}(\mathrm{M}=\mathrm{Zn}$ or $\mathrm{Ni})$ plane, wherein the increased concentration of isotropic $\mathrm{Zn}$ (II) ions induces a nonlinear variation in $\mathrm{M}-\mathrm{F}$ and $\mathrm{M}-\mathrm{N}$ bond lengths. In this, we exploit the relative donor atom hardness, where $\mathrm{M}-\mathrm{F}$ and $\mathrm{M}-\mathrm{N}$ form strong ionic and weak coordinate covalent bonds, respectively, the latter being more sensitive to substitution of $\mathrm{Ni}$ by the slightly larger
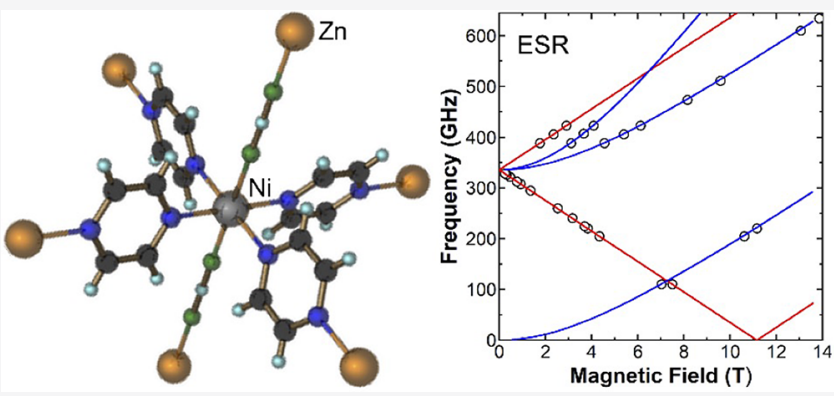
$\mathrm{Zn}$ (II) ion. In this way, we are able to tune the single-ion anisotropy of a magnetic lattice site by $\mathrm{Zn}$-substitution on nearby sites. This effect has possible applications in the field of single-ion magnets and the design of other molecule-based magnetic systems.

\section{INTRODUCTION}

The idea of symmetry breaking, in which a system crossing a critical point gravitates to a lower symmetry state, was first noted in studies of rotating incompressible fluids under hydrostatic and gravitational equilibrium by Liouville ${ }^{1}$ and $\mathrm{Jacobi}^{2}$ in 1834 . Since then, the concept has remained at the forefront of many areas of fundamental science, for instance, in theories of the early universe ${ }^{3}$ and the role of the Higgs boson in particle physics, ${ }^{4}$ catastrophe theory, ${ }^{5}$ structural phase transitions in liquids and solids, ${ }^{6}$ and magnetism. ${ }^{7}$ Recently, in various quantum materials, the observation of nematic electronic phases, in which the electrical resistivity of a previously highly symmetric material suddenly becomes anisotropic, and potential control of this effect, has excited a great deal of interest. ${ }^{8}$ While the above are examples of spontaneous symmetry breaking, here, we highlight a related effect driven by chemical intervention in which an anisotropic change in magnetic properties can be induced (and potentially controlled) by ionic substitution of an isotropic species.

We discuss the metal-organic framework (MOF) $\left[\mathrm{Zn}_{1-x} \mathrm{Ni}_{x}\left(\mathrm{HF}_{2}\right)(\mathrm{pyz})_{2}\right] \mathrm{SbF}_{6}$, where pyz is pyrazine, and show that the replacement of $\mathrm{Ni}$ (II) by isotropic $\mathrm{Zn}$ (II) ions in the solid solution results in an anisotropic expansion of the square planes hosting the metal ions, leading to a modification of the magnetic anisotropy of the $\mathrm{Ni}$ (II) spins. Our study of the solid solution is motivated by measurements ${ }^{9-11}$ on the parent MOF $\left[\mathrm{Ni}\left(\mathrm{HF}_{2}\right)(\mathrm{pyz})_{2}\right] \mathrm{SbF}_{6}$ and the fact that a variety of desirable property enhancements in MOFs have been made by introducing defects or disorder. ${ }^{12-14}$ Despite its simple structural framework, $\left[\mathrm{Ni}\left(\mathrm{HF}_{2}\right)(\mathrm{pyz})_{2}\right] \mathrm{SbF}_{6}$ exhibits complex magnetic behavior ${ }^{10}$ due to the interplay between the antiferromagnetic exchange interactions $(J-$ mediated by $\mathrm{HF}_{2}^{-}$, and $J^{\prime}-$ mediated by pyz ligands) and zero-field splitting $(D)$. To help untangle the roles of $D, J$, and $J^{\prime}$, $\left[\mathrm{Zn}_{1-x} \mathrm{Ni}_{x}\left(\mathrm{HF}_{2}\right)\left(\mathrm{pyz}_{2}\right] \mathrm{SbF}_{6}\right.$ is synthesized and crystallized ${ }^{15}$ for $x=0$ (diamagnetic host lattice) and $x=0.2$ (zerodimensional $S=1$ magnet); each is found to be isomorphous to the $x=1$ three-dimensional $S=1$ magnet. Notably, electron-spin resonance (ESR) reveals a $22 \%$ increase in $D$ from $13.3(1) \mathrm{K}\left[9.2(1) \mathrm{cm}^{-1}\right]$ to $16.2(2) \mathrm{K}\left[11.3(2) \mathrm{cm}^{-1}\right]$ as $x$ decreases from 1.0 to 0.2 . This is caused by the abovementioned nonlinear variation in M-F and M-N bond lengths (where $\mathrm{M}=\mathrm{Zn}$ or $\mathrm{Ni}$ ), resulting in anisotropic expansion of the $\mathrm{MN}_{4}$ square planes. We attribute this behavior to softer pyz-N coordination that makes the $\mathrm{M}-\mathrm{N}$ bonds more sensitive to $\mathrm{Zn}$-substitution in stark contrast to the stronger ionic M-F bonds that change very little. This mechanism for locally tuning the ligand-field of $\mathrm{NiN}_{4} \mathrm{~F}_{2}$, via $\mathrm{Zn}$-substitution of $\mathrm{Ni}$ on other lattice sites, represents a new resource in the "tool kit"

Received: December 8, 2020

Published: March 16, 2021 
employed to design and construct bespoke molecular magnets with desirable combinations of $J, J^{\prime}$, and $D$. The effect could have particular significance in the field of single-ion magnets. The focus of research in this area has shifted in recent years to encompass molecule-based magnets constructed using $d$-block elements. ${ }^{16-19}$ However, we note that the tuning mechanism we report has wide applicability and could be employed in lanthanide complexes. In addition, the changes we observed can have ramifications in a number of different fields in which dilution is used to suppress interactions, identify functionally active sites, and enhance the effectiveness of single-ion probes such as ESR, and where the additional impacts of the dilution are not always considered. ${ }^{20,21}$

\section{EXPERIMENTAL SECTION}

Synthesis and crystallization details for $\left[\mathrm{Zn}_{1-x} \mathrm{Ni}_{x}\left(\mathrm{HF}_{2}\right)(\mathrm{pyz})_{2}\right] \mathrm{SbF}_{6}$ $(x=0,0.2,1.0)$ are described in the Supporting Information. ${ }^{15}$ The crystal structures of $\left[\mathrm{M}\left(\mathrm{HF}_{2}\right)(\mathrm{pyz})_{2}\right] \mathrm{SbF}_{6}(\mathrm{M}=\mathrm{Ni}, \mathrm{Zn})$ are determined by single-crystal X-ray diffraction, while that of $\mathrm{M}=$ $\mathrm{Zn}_{0.8} \mathrm{Ni}_{0.2}$ is determined by Rietveld refinement of synchrotron powder-diffraction data. X-ray fluorescence spectroscopy is used to confirm the $\mathrm{Zn} / \mathrm{Ni}$ ratio in the mixed-metal compound. The low-field magnetization $M$ and susceptibility $\chi$ of the samples are measured using a commercial SQUID magnetometer, while high-field measurements are performed at the National High Magnetic Field Laboratory Pulsed-Field Facility using a $65 \mathrm{~T}$ short-pulse magnet. ${ }^{22}$ For the latter experiments, samples are tightly packed powders with masses of $1-2$ $\mathrm{mg}$. Data are taken in pulsed fields of up to $30 \mathrm{~T}$ and down to a base temperature of $0.5 \mathrm{~K}$. High-field, high-frequency ESR spectra of powdered samples are recorded on a spectrometer at the EMR facility of the National High Magnetic Field Laboratory. Full details of all experiments are found in the Supporting Information. ${ }^{15}$

\section{RESULTS AND DISCUSSION}

Site Disorder in $\left[\mathrm{Zn}_{0.8} \mathrm{Ni}_{0.2}\left(\mathrm{HF}_{2}\right)(\mathrm{pyz})_{2}\right] \mathrm{SbF}_{6}$. In our previous study, ${ }^{10}$ the complex magnetic behavior of $\left[\mathrm{Ni}\left(\mathrm{HF}_{2}\right)\right.$ $\left.(\mathrm{pyz})_{2}\right] \mathrm{SbF}_{6}$ and a lack of suitably sized single crystals necessitated a multitechnique approach in which we found that the values of the Hamiltonian parameters $D, J$, and $J^{\prime}$ could only be determined precisely using inelastic neutron scattering. A primary aim of the current study is therefore to focus on $D$, removing complications due to $J$ and $J^{\prime}$ by randomly diluting $\mathrm{Ni}$ (II) ions on an equivalent tetragonal lattice, thereby establishing a zero-dimensional $S=1$ magnetic framework in which $D$ can be measured unambiguously using electron spin resonance (ESR).

Hence, percolation calculations are performed to identify a Zn-substitution level sufficient to diminish the effect of exchange coupling between $\mathrm{Ni}(\mathrm{II})$ ions. This also allows the deduction of the minimum number of sites that must be occupied by $\mathrm{Ni}(\mathrm{II})$ ions on the $\mathrm{Ni} / \mathrm{Zn}$ sublattice for a cooperative magnetic phase to emerge. A simple cubic lattice, spanning a hundred unit cells in each of the three Cartesian directions, is used as a model.

While a simple cubic lattice does not represent the true symmetry of the solid solution, it is functionally equivalent to the tetragonal $\mathrm{Ni} / \mathrm{Zn}$ sublattice (see following section) for sitefilling purposes. The lattice sites are randomly occupied, representing $\mathrm{Ni}$ on the site, or unoccupied, representing $\mathrm{Zn}$ on the lattice site, such that $x$ (the concentration of $\mathrm{Ni}(\mathrm{II})$ ions) is the probability that a given site is occupied. This random distribution of $\mathrm{Ni}$ and $\mathrm{Zn}$ ions does not favor any specific bonding, nor the formation of specific clusters, and as such any $\mathrm{Ni}$ or $\mathrm{Zn}$ clustering is purely statistical. The percolation threshold, the value of $x$ for which there is a single cluster that spans from one face of the cubic lattice to an opposite face, is calculated to be $x=0.311$, in perfect agreement with ref 23 . (See Figure 1.) This demonstrates that $x=0.2$, on which our
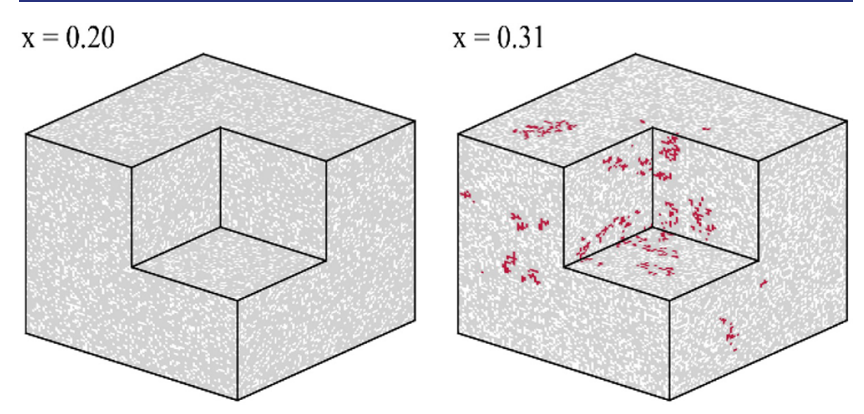

Figure 1. 3D illustrations of simple cubic lattices of face-sharing voxels for the $\mathrm{Ni}(\mathrm{II})$ concentrations $x=0.2$ and 0.31 . Only voxels that intersect the surface are shown, and an eighth of the cubic lattice has been removed to reveal the interior. The largest ordered Ni cluster is shown in red, all other sites occupied by $\mathrm{Ni}$ are given in white and sites occupied by $\mathrm{Zn}$ are shown in gray.

experiments were performed, represents a safe margin below the percolation threshold; only small clusters of exchangecorrelated $\mathrm{Ni}(\mathrm{II})$ ions will exist and hence no long-range magnetic order is expected. As shown below, the presence of small correlated clusters in the material does not adversely affect the determination of the zero-field splitting of the $\mathrm{Ni}$ (II) ion.

Crystal Structures. The three compounds $\left(\left[\mathrm{Zn}_{1-x} \mathrm{Ni}_{x}\left(\mathrm{HF}_{2}\right)\left(\mathrm{pyz}_{2}\right] \mathrm{SbF}_{6}, x=0,0.2,1.0\right)\right.$ are isomorphous and crystallize in the P4/nmm space group (Table 1). Metal cations occupy $\overline{4} 2 \mathrm{~m}$ sites and lie at the center of slightly compressed $D_{4 h}$ symmetric $\mathrm{MN}_{4} \mathrm{~F}_{2}$ pseudo-octahedra. The coordinated pyz ligands adopt a 4 symmetry about $\mathrm{M}$, each making an alternating dihedral angle $\approx \pm 73^{\circ}$. As shown in Figure 2, the structures consist of a cationic MOF-like $\left[\mathrm{M}\left(\mathrm{HF}_{2}\right)(\mathrm{pyz})_{2}\right]^{+}$framework, self-assembled from one-dimensional M-FHF-M linear chains that lie along the $c$-axis. Within the $a b$-plane, pyz ligands fuse the chains together to give twodimensional square lattices. Charge neutrality is ensured by $\mathrm{SbF}_{6}^{-}$ions that occupy pseudo-body-centered sites. These moieties are fixed in place by weak pyz $\mathrm{C}-\mathrm{H} \cdots \mathrm{F}$ interactions where $\mathrm{H} \cdots \mathrm{F}$ ranges between $2.523 \AA(\mathrm{M}=\mathrm{Ni})$ to $2.576 \AA(\mathrm{M}$ $=\mathrm{Zn})$ with the solid solution being intermediate at $2.559 \AA$.

A comparison of axial M-F and equatorial M-N bond lengths reveals key differences (Table 2 and Figure 3). First, the M-F bonds are slightly shorter than the M-N bonds. Second, the M$\mathrm{F}$ bond length changes by $1.5 \%$ across the series, indicating the strong ionicity of the interaction. Third, we observe an overall greater variation of $2.9 \%$ among $\mathrm{M}-\mathrm{N}$ coordinate bonds for different $\mathrm{M}$, which steadily increase in length from 2.113(3) $\AA$ $(\mathrm{M}=\mathrm{Ni})$ to $2.143(3) \AA\left(\mathrm{M}=\mathrm{Zn}_{0.8} \mathrm{Ni}_{0.2}\right)$ to $2.174(3) \AA(\mathrm{M}=$ $\mathrm{Zn})$.

The growth in the anisotropy ratio $[d(\mathrm{M}-\mathrm{N}) / d(\mathrm{M}-\mathrm{F})]$ with increasing $\mathrm{Zn}$ content accelerates markedly after $80 \% \mathrm{Zn}$ doping (Figure 3), despite most of the lattice sites already being occupied by isotropic $\mathrm{Zn}(\mathrm{II})$ ions; the latter have a $7.2 \%$ larger ionic radii than $\mathrm{Ni}(\mathrm{II}){ }^{24}$ To the best of our knowledge, such behavior and its impact on magnetic properties (see below) have not been previously reported. 
Table 1. X-ray Structural and Refinement Parameters for $\left[\mathrm{M}\left(\mathrm{HF}_{2}\right)(\mathrm{pyz})_{2}\right] \mathrm{SbF}_{6}\left(\mathrm{M}=\mathrm{Ni}, \mathrm{Zn}\right.$ and $\left.\mathrm{Zn}_{0.8} \mathrm{Ni}_{0.2}\right)$ Determined at 298 K

\begin{tabular}{llll}
\multicolumn{1}{c}{ Parameter } & \multicolumn{1}{c}{$\mathrm{M}=\mathrm{Ni}$} & \multicolumn{1}{c}{$\mathrm{M}=\mathrm{Zn}$} & \multicolumn{1}{c}{$\mathrm{M}^{2} \mathrm{Zn}_{0.8} \mathrm{Ni}_{0.2}$} \\
Method & Single xtl & Single xtl & \multicolumn{1}{c}{ Powder } \\
Instrument & Bruker $\mathrm{d} 8$ & Bruker $\mathrm{d} 8$ & APS 11-bm \\
$\lambda(\AA)$ & 1.54178 & 1.54178 & 0.41275 \\
Emp. formula & $\mathrm{C}_{8} \mathrm{H}_{9} \mathrm{~F}_{8} \mathrm{~N}_{4} \mathrm{NiSb}$ & $\mathrm{C}_{8} \mathrm{H}_{9} \mathrm{~F}_{8} \mathrm{~N}_{4} \mathrm{ZnSb}$ & $\mathrm{C}_{8} \mathrm{H}_{9} \mathrm{~F}_{8} \mathrm{~N}_{4} \mathrm{Zn}_{0.8} \mathrm{Ni}_{0.2} \mathrm{Sb}$ \\
Mol Wt $(\mathrm{g} / \mathrm{mol})$ & 493.65 & 500.31 & 498.97 \\
Crystal class & tetragonal & tetragonal & tetragonal \\
Space group & $P 4 / n m m$ & $P 4 / n m m$ & $P 4 / n m m$ \\
$a=b(\AA)$ & $9.9430(5)$ & $10.0871(2)$ & $10.05603(1)$ \\
$c(\AA)$ & $6.4521(5)$ & $6.4847(3)$ & $6.477771(1)$ \\
$V\left(\AA^{3}\right)$ & $637.88(8)$ & $659.82(4)$ & $655.056(2)$ \\
$Z$ & 2 & 2 & 2 \\
$\rho_{\text {exp }}\left(\mathrm{g} / \mathrm{cm}^{3}\right)$ & 2.570 & 2.518 & 2.533 \\
$\mathrm{GOF}$ or $\chi^{2}$ & 1.211 & 1.201 & 10.29 \\
$R_{1}{ }^{2}$ or $R_{\text {exp }}{ }^{a}$ & 0.0402 & 0.0293 & 0.0591 \\
$w R_{2}{ }^{a}$ or $R_{\mathrm{WP}}{ }^{a}$ & 0.0926 & 0.0686 & 0.1345
\end{tabular}

${ }^{a}$ Equations defining these parameters can be found in the deposited CIFs.

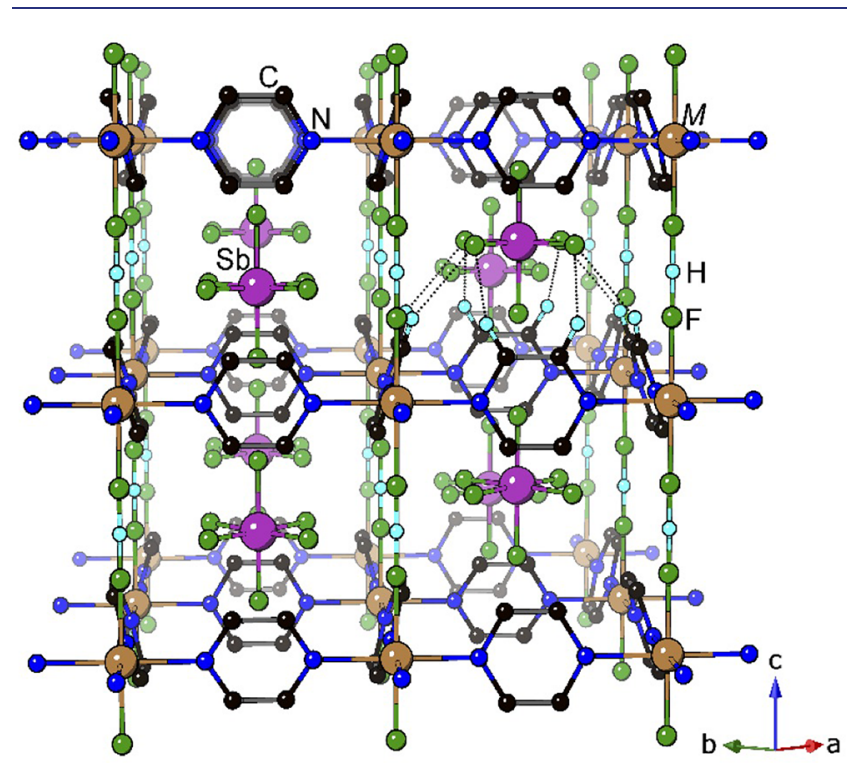

Figure 2. Representative $298 \mathrm{~K}$ crystal structure of $\left[\mathrm{M}\left(\mathrm{HF}_{2}\right)(\mathrm{pyz})_{2}\right]$ $\mathrm{SbF}_{6}$ along with the atom labeling scheme. For the $\mathrm{M}=\mathrm{Zn}_{0.8} \mathrm{Ni}_{0.2}$ solid solution, the cations are randomly distributed over the $\mathrm{M}$ sites. Dotted lines represent weak $\mathrm{C}-\mathrm{H} \cdots \mathrm{F}$ interactions between pyz and $\mathrm{SbF}_{6}^{-}$; most pyz $\mathrm{H}$ atoms are omitted for clarity.

Table 2. Selected Bond Lengths ( $\AA$ ) and Bond Angles (deg) for $\left[\mathrm{M}\left(\mathrm{HF}_{2}\right)(\mathrm{pyz})_{2}\right] \mathrm{SbF}_{6}\left(\mathrm{M}=\mathrm{Ni}, \mathrm{Zn}\right.$ and $\left.\mathrm{Zn}_{0.8} \mathrm{Ni}_{0.2}\right)$ Obtained at $298 \mathrm{~K}$

\begin{tabular}{llll} 
Bond length or angle & $\mathrm{M}=\mathrm{Ni}$ & $\mathrm{M}=\mathrm{Zn}$ & $\mathrm{M}=\mathrm{Zn}_{0.8} \mathrm{Ni}_{0.2}$ \\
M-F $(\AA)$ & $2.078(4)$ & $2.109(3)$ & $2.104(3)$ \\
$\mathrm{M}-\mathrm{N}(\AA)$ & $2.113(3)$ & $2.174(3)$ & $2.143(3)$ \\
$\mathrm{H}-\mathrm{F}(\AA)$ & $1.148(4)$ & $1.133(3)$ & $1.131(3)$ \\
$\mathrm{F} \cdots \mathrm{F}(\AA)$ & $2.296(4)$ & $2.266(3)$ & $2.260(3)$ \\
M-FHF-M $(\AA)$ & $6.4521(5)$ & $6.4847(3)$ & $6.477771(1)$ \\
M-pyz-M $(\AA)$ & $7.0308(5)$ & $7.1327(2)$ & $7.11069(1)$ \\
M-pyz dihedral (deg) & 72.9 & 73.3 & 73.4 \\
M-FHF-M (deg) & 180 & 180 & 180 \\
M-pyz-M (deg) & 180 & 180 & 180 \\
\hline
\end{tabular}

Bulk Magnetometry. SQUID magnetometer data ${ }^{15}$ on powder samples of $\left[\mathrm{Zn}_{0.8} \mathrm{Ni}_{0.2}\left(\mathrm{HF}_{2}\right)(\mathrm{pyz})_{2}\right] \mathrm{SbF}_{6}$ are shown as

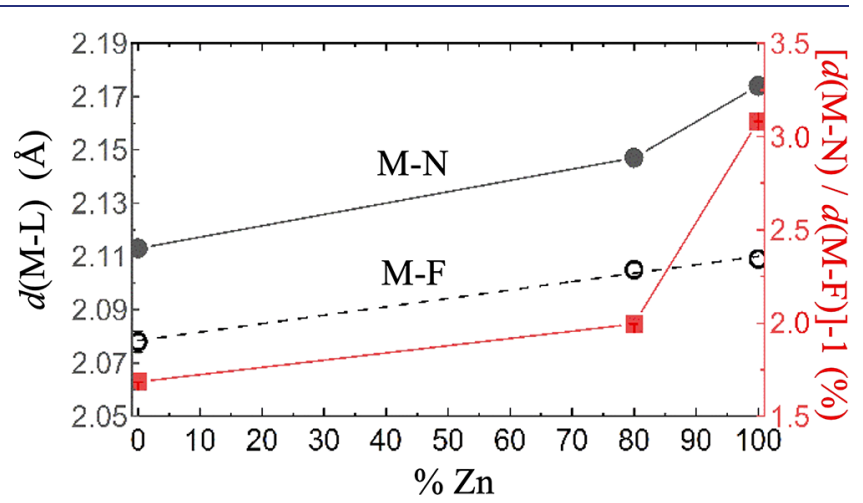

Figure 3. Plots of $M-N$ and $M-F$ bond lengths $(\AA)$ and $M_{4} F_{2}$ anisotropy ratio vs $\% \mathrm{Zn}$ composition. Lines are guides to the eye only. The closed/open circles, along with solid and dashed black lines, correspond to the left axis whereas the red squares and red line correspond to the right axis.

$\chi(T)\left(=M / H, \mu_{0} H=0.1 \mathrm{~T}\right)$ in the main plot of Figure 4 along with the previously published data for the pure $\mathrm{Ni}(\mathrm{II})$

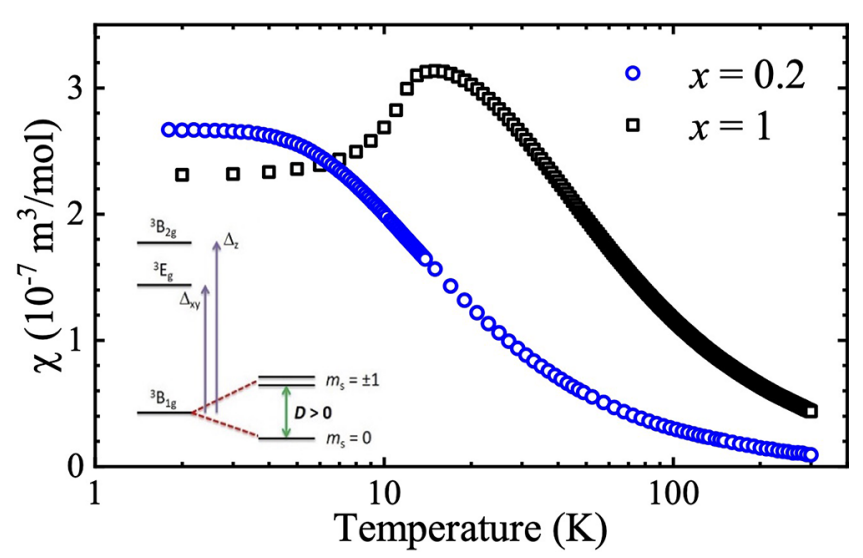

Figure 4. Susceptibility data on a log- $T$ scale for powdered samples of $\left[\mathrm{Zn}_{1-x} \mathrm{Ni}_{x}\left(\mathrm{HF}_{2}\right)(\mathrm{pyz})_{2}\right] \mathrm{SbF}_{6}, x=0.2$ (blue circles) and $x=1$ (black squares) taken in applied fields of $0.1 \mathrm{~T}$. (Inset) Illustration showing the zero-field energy-level diagram and the splitting of the $\mathrm{Ni}(\mathrm{II})$ ground-state. 
compound. ${ }^{10}$ The data for the parent material show the characteristic form of a quasi-one-dimensional $S=1$ antiferromagnet. The rapid decrease in the data on being cooled below about $12 \mathrm{~K}$ coincides with the three-dimensional long-range ordering temperature, as confirmed by heatcapacity and neutron-diffraction measurements. ${ }^{10}$ The effect of $\mathrm{Zn}$-substitution is evidenced by the data for the $x=0.2$ material, which are reminiscent of expectations for a polycrystalline $S=1$ material with small or negligible exchange interactions (see, e.g., ref 29). No evidence for a transition to long-range magnetic order is apparent, as predicted by the percolation calculations.

Below about $4 \mathrm{~K}$, the $\chi(T)$ data for $x=0.2$ reach a plateau because of the zero-field splitting of the ${ }^{3} \mathrm{~B}_{1 g} \mathrm{Ni}$ (II) groundstate in a tetragonal ligand field. ${ }^{25,26}$ While the orbital-angular momentum is largely quenched, the spin-orbit coupling perturbs the magnetic $m_{s}$ states as illustrated in the inset of Figure $4 .{ }^{27}$ On the basis of spectrochemical predictions, the $m_{s}$ $=0$ spin singlet is lower in energy owing to a weaker axial ligand-field. The $\Delta_{x y}$ and $\Delta_{z}$ excitations arise from the respective difference in the equatorial $\mathrm{Ni}-\mathrm{N}$ and axial $\mathrm{Ni}-\mathrm{F}$ ligand-fields, which lead to the observed magnetic anisotropy. $^{28}$

Pulsed-field magnetometry ${ }^{15}$ data $(T \approx 0.5 \mathrm{~K})$ for $\left[\mathrm{Zn}_{0.8} \mathrm{Ni}_{0.2}\left(\mathrm{HF}_{2}\right)(\mathrm{pyz})_{2}\right] \mathrm{SbF}_{6}$ and $\left[\mathrm{Ni}\left(\mathrm{HF}_{2}\right)(\mathrm{pyz})_{2}\right] \mathrm{SbF}_{6}$ are compared in Figure 5. The $\mathrm{M}=\mathrm{Ni}$ parent compound shows a

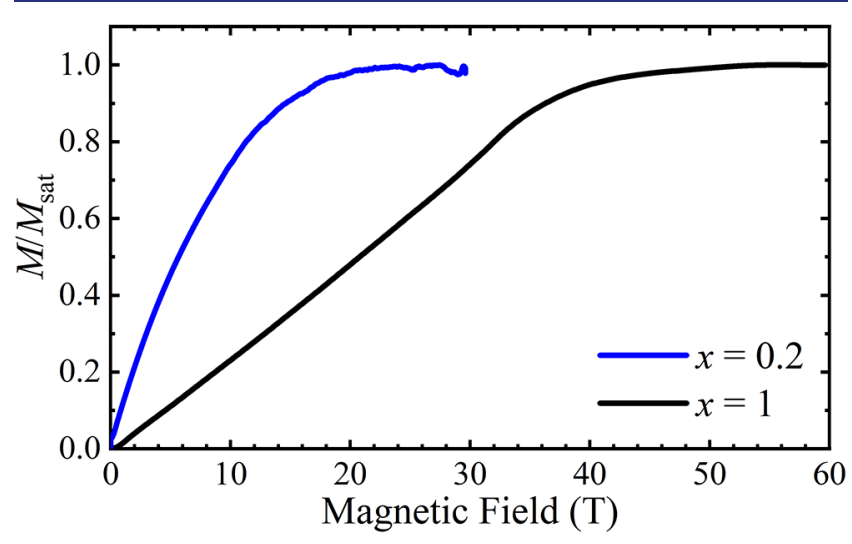

Figure 5. Plot of the magnetization normalized to the saturation value $\left(M / M_{\text {sat }}\right)$ for powdered samples of $\left[\mathrm{Zn}_{1-x} \mathrm{Ni}_{x}\left(\mathrm{HF}_{2}\right)(\mathrm{pyz})_{2}\right] \mathrm{SbF}_{6}, x=$ 0.2 (blue line) and $x=1$ (black line). The data for $x=1$ are from ref 10. For the latter, the near-linear, slow rise in $M(H)$ prior to saturation is due to AFM correlations between $\mathrm{Ni}$ ions. For both, the observed rounded approach to $M_{\text {sat }}$ is attributed to the presence of significant $D$ values.

slow, near-linear rise in $M(H)$ prior to saturation that is the hallmark of AFM correlations between $\mathrm{Ni}$ ions, ${ }^{10}$ pointing to significant $J$ values. By contrast, in the solid solution, this feature is absent, suggesting that the desired reduction of exchange interactions has been achieved. However, for both compounds, the rounded approach to $M_{\text {sat }}$ is attributable to a large value of $D$.

The magnetization data for $x=0.2$ are calibrated using lowfield SQUID $M(H)$ results performed at a similar temperature, and the saturation magnetization at high fields was found to be $M_{\text {sat }}=x \tilde{g} S=0.38(1) \mu_{\mathrm{B}} /$ formula unit where $\tilde{g}$ is the powder averaged $g$-factor. Using $\tilde{g}=2.210(6)$ derived from ESR (see below), we found that $x=0.17(1)$, in agreement with the value $[x=0.20(5)]$ obtained from X-ray fluorescence. ${ }^{15}$
Even though the $x=0.2$ material lies below the percolation threshold, it will still contain isolated regions of exchangecorrelated $\mathrm{Ni}$ (II) ions, which will have an effect on the bulk magnetometry data and the reliability of any fits to these data using a simple exchange-free model. Instead, for an unambiguous measurement of the microscopic local environment around the $\mathrm{Ni}(\mathrm{II})$ ions, we turn to ESR.

Electron Spin Resonance. Efforts to interpret ESR data from powder samples of the pure $\left[\mathrm{Ni}\left(\mathrm{HF}_{2}\right)(\mathrm{pyz})_{2}\right] \mathrm{SbF}_{6}$ endmember failed owing to the energetic competition between $D$ and $J$ regardless of the temperature and field/frequency combination used in the experiment. ${ }^{10}$ However, good quality spectra were obtained in this work ${ }^{15}$ for $\left[\mathrm{Zn}_{0.8} \mathrm{Ni}_{0.2}\left(\mathrm{HF}_{2}\right)\right.$ $\left.(\mathrm{pyz})_{2}\right] \mathrm{SbF}_{6}$. Figure 6 shows $10 \mathrm{~K}$ ESR spectra measured and

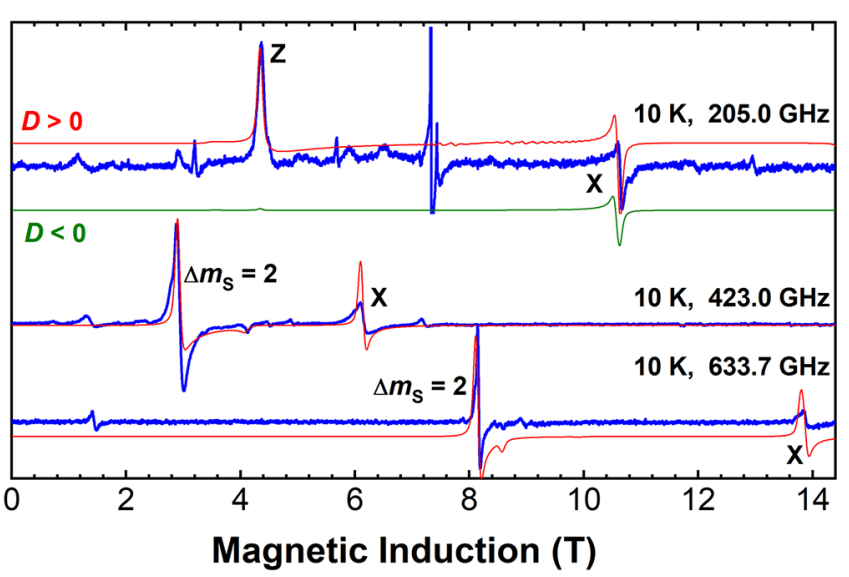

Figure 6. ESR spectra of $\left[\mathrm{Zn}_{0.8} \mathrm{Ni}_{0.2}\left(\mathrm{HF}_{2}\right)(\mathrm{pyz})_{2}\right] \mathrm{SbF}_{6}$ measured at $10 \mathrm{~K}$ for the indicated frequencies. Experimental data and simulations are shown as the blue and red lines, respectively. The green line corresponds to the same simulated parameters, but with a negative value of $D[D=-16.2(2) \mathrm{K}]$.

simulated at 205, 423 and $633.7 \mathrm{GHz}$. As expected for a powdered $S=1$ material, multiple resonances are observed between the split triplet energy levels. At a particular frequency and for the field applied along the $x, y$, or $z$-directions, two transitions that obey the ESR selection rule $\left(\Delta m_{s}= \pm 1\right)$ are possible. A general good agreement is found between the significant features in the experimental data and simulations for the $x$ - and $z$-orientations and the half-field $\Delta m_{s}=2$ transition. Formally, the half-field transition is forbidden; however, the selection rule is relaxed when the Zeeman energy is comparable to the zero-field splitting. Additional small features in the spectra are not accounted for by the simple model and are likely attributable to the presence of small, exchangecorrelated regions in the sample, as predicted by the percolation calculations. From the frequency dependences shown in Figure 7 , the derived parameters were $g_{x}=g_{y}=$ 2.240(4), $g_{z}=2.15(1), D=16.2(2) \mathrm{K}\left[11.3(2) \mathrm{cm}^{-1}\right]$.

Anisotropic Lattice Strain. The structural results described above demonstrate that the materials synthesized in this study, $\left[\mathrm{Zn}\left(\mathrm{HF}_{2}\right)(\mathrm{pyz})_{2}\right] \mathrm{SbF}_{6}$ and the solid solution $\left[\mathrm{Zn}_{0.8} \mathrm{Ni}_{0.2}\left(\mathrm{HF}_{2}\right)(\mathrm{pyz})_{2}\right] \mathrm{SbF}_{6}$, are isomorphous to $\left[\mathrm{Ni}\left(\mathrm{HF}_{2}\right)\right.$ (pyz) $)_{2}$ SbF $_{6}{ }^{9-11}$ as well as the Co- and Cu-analogs. ${ }^{30}$ In contrast to the parent $\left[\mathrm{Ni}\left(\mathrm{HF}_{2}\right)(\mathrm{pyz})_{2}\right] \mathrm{SbF}_{6}$ material, the solid solution shows no evidence of long-range magnetic correlations and instead resembles an array of zero-dimensional $S=1$ anisotropic magnets. Moreover, we obtain a $22 \%$ increase of $D$ 


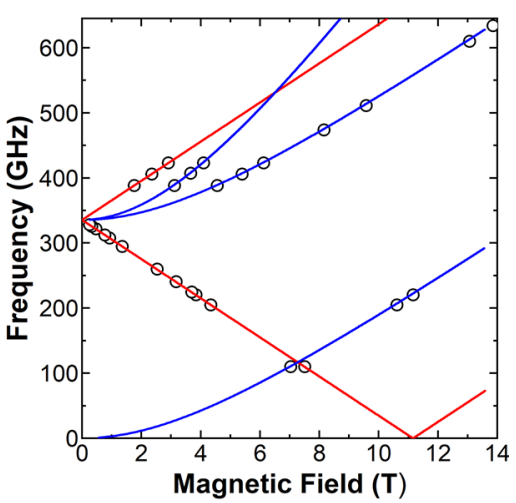

Figure 7. Frequency-dependencies of the ESR resonance fields observed in $\left[\mathrm{Zn}_{0.8} \mathrm{Ni}_{0.2}\left(\mathrm{HF}_{2}\right)(\text { pyz })_{2}\right] \mathrm{SbF}_{6}$. Red and blue traces show resonances calculated at the molecular orientations $z$ and $x$, respectively. Circles are experimental data.

from 13.3(1) $(\mathrm{M}=\mathrm{Ni})$ to $16.2(2) \mathrm{K}\left(\mathrm{M}=\mathrm{Zn}_{0.8} \mathrm{Ni}_{0.2}\right)$ (i.e., from $9.2(1) \mathrm{cm}^{-1}$ to $\left.11.3(2) \mathrm{cm}^{-1}\right)$.

The enhancement in the axial magnetic anisotropy is brought about via an anisotropic lattice strain caused by replacing $80 \%$ of $\mathrm{Ni}(\mathrm{II})$ ions with the $7.2 \%$ larger $\mathrm{Zn}$ (II). The key to this effect is that although the substituted $\mathrm{Zn}$ (II) ion is isotropic, the organic framework itself supplies the necessary anisotropy. Taking into account the difference in donor-atom hardness, with $\mathrm{F}$ being harder than $\mathrm{N}$, the effect exploits the dissimilar ionic M-F and coordinate covalent $\mathrm{M}-\mathrm{N}$ bond strengths to achieve the enhancement in $D$; weaker M-N bonds are more sensitive to substitution by the larger $\mathrm{Zn}$ (II) ion. Hence, the increased concentration of $\mathrm{Zn}$ causes a nonlinear change in $\mathrm{M}-\mathrm{N}$ bond lengths compared to M-F and yields an anisotropic lattice expansion within the $\mathrm{MN}_{4}$ plane. Remarkably, the comparatively small percentage change in bond lengths leads to the significant boost in $D$.

\section{CONCLUSION}

Our findings reveal a novel mechanism by which strain can be used to adjust the ligand-field of magnetic ions and hence their local magnetic anisotropy through the introduction of nonmagnetic ions on nearby lattice sites. We suggest that in this way, the combination of anisotropic organic frameworks and metal ions of different radii may be exploited as an approach to tune the single-ion properties of magnetically isolated spins. These results will be useful in the investigation and control of magnetization reversal and slow relaxation in self-assembled arrays of single-ion magnets ${ }^{16-19}$ composed of $d$ - or $f$-elements for use in spin-based electronic devices.

\section{ASSOCIATED CONTENT}

\section{SI Supporting Information}

The Supporting Information is available free of charge at https://pubs.acs.org/doi/10.1021/jacs.0c12516.

Full experimental details, including syntheses, X-ray fluorescence, single crystal X-ray diffraction and data collection, synchrotron powder diffraction and Rietveld analysis, SQUID and pulsed-field magnetometry and electron-spin resonance (PDF)

\section{Accession Codes}

CCDC 2026750-2026752 contain the supplementary crystallographic data for this paper. These data can be obtained free of charge via www.ccdc.cam.ac.uk/data_request/cif, or by emailing data request@ccdc.cam.ac.uk, or by contacting The Cambridge Crystallographic Data Centre, 12 Union Road, Cambridge CB2 1EZ, UK; fax: +44 1223336033.

\section{AUTHOR INFORMATION}

\section{Corresponding Authors}

Jamie L. Manson - Department of Chemistry, Biochemistry \& Physics, Eastern Washington University, Cheney, Washington 99004, United States; (1) orcid.org/0000-0003-2692-3500; Email: jmanson@ewu.edu

Paul A. Goddard - Department of Physics, University of Warwick, Coventry CV4 7AL, U.K.; Email: p.goddard@ warwick.ac.uk

John Singleton - National High Magnetic Field Laboratory, Pulsed-Field Facility, Los Alamos National Laboratory, Los Alamos, New Mexico 87545, United States; 이이.org/ 0000-0001-6109-6905; Email: john.singleton@ physics.ox.ac.uk

\section{Authors}

Samuel P. M. Curley - Department of Physics, University of Warwick, Coventry CV4 7AL, U.K.

Robert C. Williams - Department of Physics, University of Warwick, Coventry CV4 7AL, U.K.

David Walker - Department of Physics, University of Warwick, Coventry CV4 7AL, U.K.; o orcid.org/00000002-8583-4279

Andrew Ozarowski - National High Magnetic Field Laboratory, Florida State University, Tallahassee, Florida 32310, United States; 이이. orcid.org/0000-0001-6225-9796

Roger D. Johnson - Department of Physics \& Astronomy, University College London, London WC1E 6BT, U.K.

Anuradha M. Vibhakar - Clarendon Laboratory, Department of Physics, Oxford University, Oxford OX1 3PU, U.K.

Danielle Y. Villa - Department of Chemistry, Biochemistry \& Physics, Eastern Washington University, Cheney, Washington 99004, United States

Melissa L. Rhodehouse - Department of Chemistry, Biochemistry \& Physics, Eastern Washington University, Cheney, Washington 99004, United States

Serena M. Birnbaum - National High Magnetic Field Laboratory, Pulsed-Field Facility, Los Alamos National Laboratory, Los Alamos, New Mexico 87545, United States

Complete contact information is available at:

https://pubs.acs.org/10.1021/jacs.0c12516

\section{Notes}

The authors declare no competing financial interest.

\section{ACKNOWLEDGMENTS}

Work at EWU was supported by the U.S. National Science Foundation (NSF) under grant No. DMR-1703003. J.L.M. gratefully acknowledges the NSF (CHE-1827313) for purchase of the single-crystal X-ray diffractometer located at Whitworth University. This project has received funding from the European Research Council (ERC) under the European Union's Horizon 2020 research and innovation program (grant agreement No. 681260). We thank the University of Warwick X-ray Diffraction Research Technology Platform for the XRF measurements. R.D.J. acknowledges support from a Royal Society University Research Fellowship. We thank S. H. Lapidus (X-ray Science Division, Advanced Photon Source, Argonne National Laboratory) for synchrotron powder data 
collection on 11-BM. Use of the APS, an Office of Science User Facility operated for the U.S. Department of Energy (DOE) Office of Science by ANL, was supported by the U.S. DOE under Contract No. DEAC02-06CH11357. A portion of this work was performed at the NHMFL, which is supported by NSF Cooperative Agreement No. DMR-1644779 and the State of Florida. J.S. acknowledges support from the Strongly Correlated Magnets thrust of the DoE BES "Science in 100T" program and a visiting professorship at Oxford University. Data presented resulting from the UK effort will be made available at https://wrap.warwick.ac.uk/148935/.

\section{REFERENCES}

(1) Liouville, J. Sur la figure d'une masse fluide homogène, en équilibre et douée d'un mouvement de rotation. Journal de l'Ecole Polytechnique 1834, 14, 289-296.

(2) Jacobi, C. G. J. Über die figur des gleichgewicht. Ann. Phys. 1834, 109, 229-238.

(3) R., Penrose The Road to Reality; a Complete Guide to the Laws of the Universe; Alfred A. Knopf, New York, 2005; see especially Section 28.

(4) P., Higgs Evading the Goldstone Theorem; Nobel Prize Lecture (2013); www.nobelprize.org/uploads/2018/06/higgs-lecture, downloaded 29 September 2020.

(5) R., Gilmore Catastrophe Theory for Scientists and Engineers; Dover Publications Inc.: New York, 1993; see especially Chapters 10 and 15.

(6) Martin, T. Dove, Structure and Dynamics; an Atomic View of Materials; Oxford University Press: Oxford, 2003; Chapter 12.

(7) Landau, L. D.; Lifshitz, E. M.; Pitaevskii, L.P. Electrodynamics of Continuous Media, (2nd ed.). Butterworth-Heinemann: Oxford, 1983.

(8) Helm, T.; Grockowiak, A.; Balakirev, F.; Singleton, J.; Betts, J. B.; Shirer, K. W.; Koenig, M.; Foerster, T.; Bauer, E. D.; Ronning, F.; Tozer, S. W.; Moll, P. J. Non-monotonic pressure dependence of high-field nematicity and magnetism in CeRhIn ${ }_{5}$. Nat. Commun. 2020, 11, 3482. and references therein.

(9) Manson, J. L.; Lapidus, S. H.; Stephens, P. W.; Peterson, P. K.; Carreiro, K. E.; Southerland, H. I.; Lancaster, T.; Blundell, S. J.; Steele, A. J.; Goddard, P. A.; Pratt, F. L.; Singleton, J.; Kohama, Y.; McDonald, R. D.; del Sesto, R. E.; Smith, N. A.; Bendix, J.; Zvyagin, S. A.; Kang, J.; Lee, C.; Whangbo, M.-H.; Zapf, V. S.; Plonczak, A. Structural, Electronic, and Magnetic Properties of Quasi-1D Quantum Magnets $\left[\mathrm{Ni}\left(\mathrm{HF}_{2}\right)(\mathrm{pyz})_{2}\right] \mathrm{X}\left(\mathrm{pyz}=\right.$ pyrazine; $\left.\mathrm{X}=\mathrm{PF}_{6}{ }^{--}, \mathrm{SbF}_{6}{ }^{--}\right)$ Exhibiting Ni-FHF-Ni and Ni-pyz-Ni Spin Interactions. Inorg. Chem. 2011, 50, 5990-6009.

(10) Brambleby, J.; Manson, J. L.; Goddard, P. A.; Stone, M. B.; Johnson, R. D.; Manuel, P.; Villa, J. A.; Brown, C. M.; Lu, H.; Chikara, S.; Zapf, V.; Lapidus, S. H.; Scatena, R.; Macchi, P.; Chen, Y.-S.; Wu, L.-C.; Singleton, J. Combining microscopic and macroscopic probes to untangle the single-ion anisotropy and exchange energies in an $S=$ 1 quantum antiferromagnet. Phys. Rev. B: Condens. Matter Mater. Phys. 2017, 95, 134435.

(11) Manson, J. L.; Manson, Z. E.; Sargent, A.; Villa, D. Y.; Etten, N. L.; Blackmore, W. J. A.; Curley, S. P. M.; Williams, R. C.; Brambleby, J.; Goddard, P. A.; Ozarowski, A.; Wilson, M. N.; Huddart, B. M.; Lancaster, T.; Johnson, R. D.; Blundell, S. J.; Bendix, J.; Wheeler, K. A.; Lapidus, S. H.; Xiao, F.; Birnbaum, S.; Singleton, J. Enhancing easy-plane anisotropy in bespoke $\mathrm{Ni}(\mathrm{II})$ quantum magnets. Polyhedron 2020, 180, 114379.

(12) Cheetham, A. K.; Bennett, T. D.; Coudert, F.-X.; Goodwin, A. L. Defects and disorder in metal organic frameworks. Dalton Trans 2016, 45, 4113-4126.

(13) Livage, C.; Forster, P. M.; Guillou, N.; Tafoya, M. M.; Cheetham, A. K.; Ferey, G. Effect of Mixing of Metallic Cation on the Topology of Metal-Oxide Networks. Angew. Chem., Int. Ed. 2007, 46, 5877-5879.

(14) Serpaggi, F.; Luxbacher, T.; Cheetham, A. K.; Ferey, G. Dehydration and Rehydration Processes in Microporous Rare-Earth
Dicarboxylates: A Study by Thermogravimetry, Thermodiffractometry and Optical Spectroscopy. J. Solid State Chem. 1999, 145, 580-586.

(15) See Supporting Information at [URL will be inserted by publisher] for additional details of synthesis, experimental techniques and theory.

(16) Frost, J. M.; Harriman, K. L. M.; Murugesu, M. The rise of 3 $d$ single-ion magnets in molecular magnetism: towards materials from molecules? Chem. Sci. 2016, 7, 2470.

(17) Craig, G. A.; Murrie, M. 3d single-ion magnets. Chem. Soc. Rev. 2015, 44, 2135.

(18) Miklovic, J.; Valigura, D.; Boca, R.; Titis, J. A mononuclear $\mathrm{Ni}(\mathrm{ii})$ complex: a field induced single-molecule magnet showing two slow relaxation processes. Dalton Trans 2015, 44, 12484.

(19) Titis, J.; Rajnak, C.; Valigura, D.; Boca, R. Field influence on the slow magnetic relaxation of nickel-based single ion magnets. Dalton Trans 2018, 47, 7879.

(20) D'yakonov, V. P.; Levchenko, G. G.; Fita, I. M.; Tsintsadze, G. A. Spin-spin interactions and magnetic ordering in ferromagnets with single-ion anisotropy. Zh. Eksp. Teor. Fiz. 1984, 87, 2193.

(21) Pardi, L. A.; Hassan, A. K.; Hulsbergen, F. B.; Reedijk, J.; Spek, A. L.; Brunel, L.-C. Direct Determination of the Single-Ion Anisotropy in a One-Dimensional Magnetic System by High-Field EPR Spectroscopy; Synthesis, EPR, and X-ray Structure of $\mathrm{Ni}_{x} \mathrm{Zn}_{1-x}\left(\mathrm{C}_{2} \mathrm{O}_{4}\right)(\mathrm{dmiz})_{2}[x=0.07]$. Inorg. Chem. 2000, 39, 159.

(22) Goddard, P. A.; Singleton, J.; Sengupta, P.; McDonald, R. D.; Lancaster, T.; Blundell, S. J.; Pratt, F. L.; Cox, S.; Harrison, N.; Manson, J. L.; Southerland, H. I.; Schlueter, J. A. Experimentally determining the exchange parameters of quasi-two-dimensional Heisenberg magnets. New J. Phys. 2008, 10, 083025.

(23) Martins, P. H. L.; Plascak, J. A. Percolation on two- and threedimensional lattices. Phys. Rev. E: Stat. Phys., Plasmas, Fluids, Relat. Interdiscip. Top. 2003, 67, 046119.

(24) (a) Shannon, R. D.; Prewitt, C. T. Effective ionic radii in oxides and fluorides. Acta Crystallogr., Sect. B: Struct. Crystallogr. Cryst. Chem. 1969, B25, 925-945. (b) Shannon, R. D. Revised effective ionic radii and systematic studies of interatomic distances in halides and chalcogenides. Acta Crystallogr., Sect. A: Cryst. Phys., Diffr., Theor. Gen. Crystallogr. 1976, A32, 751-767.

(25) Lever, A. B. P. Inorganic Electronic Spectroscopy; Elsevier: New York, 1984.

(26) Figgis, B. N.; Hitchman, M. A. Ligand Field Theory and its Applications; Wiley-VCH: New York, 1999.

(27) Boça, R. Zero-field splitting in metal complexes. Coord. Chem. Rev. 2004, 248, 757-815.

(28) Kahn, O. Molecular Magnetism; VCH Publishers: Weinheim, 1993.

(29) Blackmore, W. J. A.; Brambleby, J.; Lancaster, T.; Clark, S. J.; Johnson, R. D.; Singleton, J.; Ozarowski, A.; Schlueter, J. A.; Chen, Y.S.; Arif, A. M.; Lapidus, S.; Xiao, F.; Williams, R. C.; Blundell, S. J.; Pearce, M. J.; Lees, M. R.; Manuel, P.; Villa, D. Y.; Villa, J. A.; Manson, J. L.; Goddard, P. A. Determining the anisotropy and exchange parameters of polycrystalline spin-1 magnets. New J. Phys. 2019, 21, 093025.

(30) Brambleby, J.; Goddard, P. A.; Johnson, R. D.; Liu, J.; Kaminski, D.; Ardavan, A.; Steele, A. J.; Blundell, S. J.; Lancaster, T.; Manuel, P.; Baker, P. J.; Singleton, J.; Schwalbe, S. G.; Spurgeon, P. M.; Tran, H. E.; Peterson, P. K.; Corbey, J. F.; Manson, J. L. Magnetic ground state of the two isostructual polymeric quantum magnets $\left.\left[\mathrm{Cu}\left(\mathrm{HF}_{2}\right) \text { (pyrazine }\right)_{2}\right] \mathrm{SbF}_{6}$ and $\left[\mathrm{Co}\left(\mathrm{HF}_{2}\right)(\text { pyrazine })_{2}\right] \mathrm{SbF}_{6}$ investigated with neutron powder diffraction. Phys. Rev. B: Condens. Matter Mater. Phys. 2015, 92, 134406. 